This document is published in:

Journal of Econometrics, (2008), 147 (2), 247-257.

DOI: http://dx.doi.org/10.1016/j.jeconom.2008.09.014

(C) 2008 Elsevier B.V. 


\title{
Demand and supply estimation biases due to omission of durability
}

\author{
Jiawei Chen ${ }^{\mathrm{a}, *}$, Susanna Esteban ${ }^{\mathrm{b}}$, Matthew Shum ${ }^{\mathrm{c}}$ \\ a Department of Economics, University of California-Irvine, Irvine, CA 92697, USA \\ ${ }^{\mathrm{b}}$ Department of Economics, Universidad Carlos III de Madrid, Getafe, 28903 Madrid, Spain \\ ${ }^{\mathrm{c}}$ Division of Humanities and Social Sciences, California Institute of Technology, Pasadena, CA 91125, USA
}

\author{
JEL classification: \\ C13 \\ C73 \\ L11 \\ L13 \\ L62 \\ Keywords: \\ Durable goods \\ Secondary markets \\ Estimation bias \\ Demand elasticity \\ Mark-up
}

A R T I C L E I N F O

\begin{abstract}
A B S T R A C T
We build a dynamic equilibrium model of a durable goods oligopoly with a competitive secondary market to evaluate the bias in estimating the structural parameters of demand and supply when durability is omitted. We simulate data from our dynamic model and use them to estimate the model's static counterpart. We find that the static estimate of the elasticity of demand is an overestimate of the true elasticity and that the static estimate of the markup is an underestimate. Our results provide a benchmark on the magnitude and sign of the bias when static models are used for economic inference.
\end{abstract}

\section{Introduction}

Durability and secondary markets affect the behavior of profitmaximizing oligopolistic firms by making their decision problems dynamic and thus modifying their price and quantity choices. In this paper, we seek to quantify the bias in estimating the structural parameters of the model when omitting durability and secondary markets. Our approach is to obtain simulated data from our dynamic durable-goods model and then use these data to estimate the static counterpart of the model that omits durability. Our goal is to quantify and sign the bias in estimating the structural parameters of demand and technology.

Durability and secondary markets create dynamics in the problems of consumers and firms. As a durable good, the product is an asset which consumers can either use over multiple periods, delaying their return to the primary market, or choose to scrap and purchase a replacement. The consumers' decisions whether to delay or to purchase - depend on their expectations on future primary market prices, which create forward-looking dynamics in the demand function and thus on the firms' decision problems. However, with a frictionless secondary market,

\footnotetext{
* Corresponding author. Tel.: +1 949824 3189; fax: +1 9498242182. E-mail addresses: jiaweic@uci.edu (J. Chen), sesteban@eco.uc3m.es (S. Esteban), mshum@caltech.edu (M.Shum).
}

consumers can fully recover the value of their investment by trading their asset in the secondary market in every period, making unnecessary their choice between delay and purchase and thus eliminating the forward-looking dependence of current demand on future expected primary market prices. However, with secondary markets, forward-looking dependence remains present through the implicit rental price: consumers pay for the oneperiod use of the asset the difference between its current price and the expected resale price in the following period, which yields the dependence of demand on expected future secondary market prices and on expected future primary market prices as new and used goods are substitutes in consumption.

As pointed out by Coase (1972), the forward-looking dependence in the demand function creates dynamics in the problem of firms and is a source of time inconsistency: the firm can raise its profits by announcing high future primary market prices (low production levels) since this will drive up expected secondary market prices and positively increase the consumers' current willingness to pay for new goods, which allows the firm to raise current prices. ${ }^{1}$ Nonetheless, consumers are rational and anticipate that after current profits have been earned, the firm wants to revise its previous announcement, by lowering current prices (raising output),

\footnotetext{
${ }^{1}$ The Coase conjecture states that, if the good is infinitely durable, does not depreciate, and the firm can adjust price instantaneously, a monopolist prices immediately at marginal cost.
} 
and thus behaves time inconsistently. In this paper, we assume consumers possess rational expectations and characterize the time consistent equilibrium. ${ }^{2}$

In addition to forward-looking dependence, the secondary market also creates the dependence of demand on past output as it trades in the contemporaneous secondary market and becomes a source of competition for the firm. The competitive pressure created by the secondary market will reduce the firm's output. Liang (1999) points out that this reduction in future output results in a production strategy closer to the full commitment solution.

In this paper, we build a full equilibrium time consistent dynamic oligopoly model of a durable goods market - the car market - which accounts for the durability of the product, its trade in active secondary markets and the forward-looking behavior of both consumers and firms. We simulate data for the structural dynamic model drawing from the calibrated parameter values in Chen et al. (2007). We then measure and sign the bias in estimating the structural parameters of the model while neglecting durability and secondary markets by estimating the deep parameters of demand and technology with a static model.

An advantage of our data-generating approach, which is feasible because of having a full equilibrium model of demand and supply, is that the truth is "known" to us, which gives us a welldefined comparison point to evaluate the biases in our parameter estimates. Alternatively, we could have estimated the dynamic and static versions of the model and compared the estimated parameter values. However, in this case all we could say is that the estimates are different, but we could not make statements on the relative accuracy of the approaches.

Our results show that ignoring dynamics leads to upwardlybiased (in absolute terms) estimates of the demand elasticities and downwardly-biased estimates of the markup. The markup bias is larger in magnitude that the elasticity of demand bias, which suggests that a correct specification of the firms' behavior is important when drawing policy implications for durable-goods markets. Additionally, given the computation and data constraints in estimating full equilibrium dynamic models, our results shed light on the magnitude and sign of the biases when having to obtain economic inference from static models.

To summarize, the main contribution of our work is to quantify and sign the biases for supply of estimating static models. As already shown in the literature, the demand-side estimates will be biased if we estimate models that ignore forward-looking dynamics. The estimates on the supply-side, however, the firms' markups, will also be biased because both the demand elasticities are mismeasured and because the first-order conditions to the firms' problem are incorrectly specified since the firms' problems are forward looking.

\subsection{Literature overview}

Our work relates to the literature seeking to quantify the biases when estimating static models that are misspecified because the characteristics of the product make the problems of consumers and firms inherently dynamic, as it is the case for durable goods. ${ }^{3}$

\footnotetext{
2 There is a large theoretical literature analyzing how durability erodes market power and validating the Coase conjecture: see Ausubel and Deneckere (1989), Bond and Samuelson (1984), Bulow (1982), Gul et al. (1986) and Stokey (1981). See Waldman (2003) for a recent survey of the durable-goods literature.

3 Other papers have studied markets that have dynamics similar to those of durable goods (for example, goods for which there is satiation in consumption and storables) and have also quantified, with demand-side models, the bias that results when the model estimated is static. Hartmann (2006) studies an intertemporal satiation problem (playing golf); Hendel and Nevo (2006) and Sun et al. (2003) look at markets where consumers can store and hold inventories of the good.
}

Overall, we differ from the existing literature in our focus on both the demand and supply side biases and on our approach to quantify them. ${ }^{4}$ Having a full equilibrium model allows us to take a different approach - a simulation/estimation approach - to measure the misspecification bias.

Our approach is similar to the one taken in Sun et al. (2003) who analyze the bias in a storable goods market by simulating data with a dynamic model and estimating a myopic version of it. Also in this literature, Gowrisankaran and Rysman (2006) build a demand-side model of the DVD market (an example of a durable good) and estimate the dynamic and static versions of the model. ${ }^{5}$ They find that the static model tries to explain the consumers' delay when purchasing by increasing the variance for the valuation of DVDs. Carranza (2007) also estimates dynamic and static demand-side models of the digital cameras market and finds that ignoring dynamics results in low estimates for the taste parameters. Gordon (2006) estimates a demand-side model with uncertain product quality and price changes. He finds that the estimation of a model without forward-looking consumers underestimates price elasticities.

A different approach in accounting for the importance of dynamics is taken by Chevalier and Goolsbee (2003) and Melnikov (2000) who quantify the importance of forward looking dynamics by estimating the discount factor (or inferring it from the parameter estimates). Both find evidence of consumers being forward looking. Erdem et al. (2003) estimate a dynamic demandmodel of stock-piling behavior and find that the estimated elasticities depend on how current price changes affect the expectations on future price changes.

Our work also relates to the growing literature estimating demand-side models of durable goods, ${ }^{6}$ Adda and Cooper (2000b), Adda and Cooper (2000a), ${ }^{7}$ Gordon (2006), Song and Chintagunta (2003), Gowrisankaran and Rysman (2006), Carranza (2007), Gordon (2006), Berkovec (1985), Rust (1985) and Stolyarov (2002), with some papers accounting for transaction costs, in which consumers solve an optimal stopping problem, and secondary markets. $^{8}$ Overall, compared to this literature, the complexity added by having a supply side problem forces us to simplify the heterogeneity in demand.

Esteban and Shum (2007), Suslow (1986), Porter and Sattler (1999) and Ramey (1989) derive and estimate full equilibrium models of durable goods that incorporate a supply side problem but have to rely on simpler demand environments than ours. ${ }^{9}$ Most

\footnotetext{
4 One exception is Esteban (1999) which measures, at a theoretical level, the difference in the imputed parameters if one were to estimate a static model while the data was generated by a dynamic monopoly durable-goods model. The results are derived for a simplified version of the model in Esteban and Shum (2007).

5 Endogenous product characteristics also yield dynamics in the problems of consumers and firms: consumers decides whether to purchase now or delay based on their expectation on future quality adjustments, which creates the forward looking dependence on demand that is responsible for the firms' consistency problems. Wang (2007) studies empirically this problem assuming that consumers do not have any foresight about the evolution of prices and characteristics.

6 The rich complexity of the automobile industry has resulted in an extensive literature addressing questions other than the dynamics resulting from the durability of the product. Therefore, papers like Bresnahan (1987), Berry et al. (1995), Goldberg (1995), Petrin (2002) and Clerides (2003), among others, have employed full equilibrium models without forward-looking behavior in the problem of consumers and firms.

7 This paper incorporates firms but the market is perfectly competitive.

8 The importance of the adverse selection problem that arises from secondary markets has also been analyzed in the literature: see Akerlof (1970), Hendel and Lizzeri (1999), House and Leahy (2000) and Bond (1982) for an empirical contribution.

9 Carlton and Gertner (1989) analyzes the theoretical implications of mergers on oligopolistic durable goods producers. Esteban (2002) analyzes the implications of imperfect competition on the dynamics of market aggregates. Iizuka (2007) estimates a reduced-form model of the textbook market where new editions are introduced to kill-off the secondary market.
} 
closely related to our present work is Tanaka (2007) and Chen et al. (2007) who alleviate the problems of restricting the demand- side problem by assuming logit-demand models, where the former allows for persistent time-varying production costs while the latter incorporates transaction costs (relating closer to the demand-side literature). Nair (2004) estimates a dynamic full equilibrium model of demand and supply without secondary markets of the consolevideo game market, where consumers solve an optimal stopping problem. Carranza (2008) estimates a full equilibrium of the digital cameras market where the dynamics arise from the firms deciding whether to introduce new models. Goettler and Gordon (2008) estimate a dynamic model of durable goods where firms make dynamic pricing and investment decisions to improve the product.

Our paper is organized as follows. Section 2 derives the dynamic model. Section 2 addresses the parameterization of the datagenerating dynamic model and Section 4 evaluates the estimation biases when omitting durability. Section 5 concludes.

\section{Model}

Consider a durable goods oligopolistic industry with a secondary market. Both firms and consumers are forward looking. The model is cast in discrete time and has an infinite horizon. In what follows, we use the car industry to illustrate our model.

The life of a car consists of $J$ stages, starting with being "new". We assume all new cars are homogeneous. The only characteristic of a car is its quality, and when a car depreciates from one stage to the next, its quality deteriorates. To simplify the state space while keeping the differentiation structure between new and used cars, we assume that cars differ in their quality only when they are of different stages, so that all cars of the same stage are homogeneous even if they are produced by different firms. Let $\alpha_{j}>0$, for $j=$ $1, \ldots, J$, denote the cars' qualities in different stages. Let " 0 " index the outside good, or "no car", and normalize the quality of the outside good as $\alpha_{0}=0$.

In the car industry, as in many other durable good industries, a product lives for many periods, where a period is defined by a year. In fact, the average age of cars in the US was 9 years according to the 2001 National Household Travel Survey (NHTS). As a result, at any point in time the number of used cars in existence is many times larger than that of new cars. This creates a modeling difficulty in the dynamic framework: if each stage of a car's life corresponds to one period, and if we model cars as living for many periods by having a large $J$ (for example, $J=9$ or above), then the state space is huge and the heavy computational burden makes the model intractable. Instead, if we have a small $J$ (for example, $J=2$ or 3 ), then the number of used cars in existence is only slightly larger than that of new cars, which is far from reality and makes calibration impossible.

To address this problem, we assume stochastic depreciation of used cars, that is, at the end of each period, each used car depreciates into the next stage with probability $\delta \in(0,1)$. Formally, at the end of each period, goods (cars or the outside good) depreciate according to the transition function

$$
d(j)=\left\{\begin{array}{l}
0 \quad \text { if } j=0, \\
2 \text { if } j=1, \\
j \text { with probability } 1-\delta, \text { and } j+1 \text { with probability } \delta \\
\text { if } j=2, \ldots, J-1, \\
J \text { with probability } 1-\delta, \text { and } 0 \text { with probability } \delta \\
\text { if } j=J .
\end{array}\right.
$$

Here $d(j)$ denotes the next-period's index of a good that is currently indexed by $j, j=0,1, \ldots, J$. The depreciation of the outside good (to itself) and of new cars (to second-stage cars), i.e., just used cars, is deterministic, whereas the depreciation of used cars into different used car of different stages is stochastic.
With stochastic depreciation of used cars, even if $J$ is small, the number of used cars in existence can still be much larger than that of new cars, fitting the empirical observation, and yet there is only a small number of aggregate state variables, which makes the model tractable.

On the supply side, the marginal cost of producing new cars is the same across firms and constant in output, with an industrywide cost shock in each period. Specifically, the marginal cost in period $t$ for each firm is

$c_{t}=\bar{c}+v_{t}$,

where $v_{t}$ is the i.i.d. cost shock,

$v_{t}= \begin{cases}-\tilde{c} & \text { with probability } \rho, \\ 0 & \text { with probability } 1-2 \rho, \\ \tilde{c} & \text { with probability } \rho,\end{cases}$

with $\bar{c}$ and $\tilde{c}$ being positive constants, $\tilde{c}<\bar{c}$, and $\rho \in(0,1)$. The cost shock introduces randomness into the model at the aggregate level, so that there are fluctuations in the simulated price and quantity data, which will be needed for the estimation.

The timing of events is as follows. At the beginning of each period, consumers inherit either used cars or the outside good from their decisions in the previous period, and the cost shock is realized and known to all agents. Then firms and consumers simultaneously make production and purchase/sale decisions, whereby firms obtain per-period profits and consumers enjoy per-period utility from consumption. At the end of each period, goods depreciate and a new period arrives.

\subsection{Consumers' problem}

There is a continuum of consumers of size $M$, with a generic consumer denoted by $i$. Consumers are heterogeneous in their valuations of goods, which perturb their choices of goods in every period. Let $\vec{\epsilon}_{i t} \equiv\left(\epsilon_{i 0 t}, \epsilon_{i 1 t}, \ldots, \epsilon_{i j t}\right)$ be the vector of idiosyncratic shocks of consumer $i$ for period $t$, with $\epsilon_{i j t}$ being i.i.d. across $(i, j, t)$.

We let $r_{i t}=0,2, \ldots, J$ denote the index of the good (used cars or the outside good) owned by the consumer $i$ at the beginning of period $t$. Because depreciation takes place at the end of each period, at the beginning of each period, before purchasing, no consumer owns a new car, so $r_{i t} \neq 1, \forall i, \forall t$. We let $K_{j t}$, for $j=0,1, \ldots, J$, denote the fraction of consumers in the population who own good $j$ at the beginning of period $t$, with $K_{1 t}=0$ by construction, and define the vector $\vec{B}_{t}=\left(K_{2 t}, \ldots, K_{I t}\right)^{\prime}$ to be the vector of used car stocks at the beginning of period $t$. Note that $K_{0 t}=1-\left(K_{2 t}+\cdots+K_{J t}\right)$.

To write the consumers' problem in a dynamic programming framework, we define the aggregate and individual states as follows. The aggregate state is $\vec{B}_{t}$ and $c_{t}$. For a consumer $i$ who owns $r_{i t} \in\{0,2, \ldots, J\}$ at the beginning of period $t$, the individual state consists of $\vec{B}_{t}, c_{t}, r_{i t}, \vec{p}_{t}$ and $\vec{\epsilon}_{i t}$. Given the individual state, consumer $i$ 's period-t utility if she chooses $s_{i t} \in\{0,1, \ldots, J\}$ for consumption is

$u\left(s_{i t}, r_{i t}, \vec{\epsilon}_{i t}, \vec{p}_{t}\right)=\alpha_{s_{i t}}+\gamma \cdot\left(p_{r_{i t} t}-p_{s_{i t} t}\right)+\epsilon_{i s_{i t} t}$,

where $\gamma$ measures the consumer's marginal utility of money, $\vec{p}_{t}=$ $\left(p_{0 t}, p_{1 t}, \ldots, p_{J t}\right)$ is the price vector in period $t$, and $p_{j t}$ denotes the price of good $j$ in period $t$, with the convention that $p_{0 t}=0$ for all $t$.

In the Markov perfect equilibrium (MPE), the aggregate state transition is given by $\vec{B}^{\prime}=H^{*}(\vec{B}, c)$, and the mapping from the aggregate state to current prices is given by $\vec{p}=G^{*}(B, c)$, where both are functions of the MPE equilibrium decision rules. Therefore, in equilibrium, consumer $i$ 's per-period utility if she chooses $s_{i}$ for consumption can be re-written as

$$
\begin{aligned}
u\left(s_{i}, r_{i}, \vec{\epsilon}_{i}, \vec{p}\right) & =u\left(s_{i}, r_{i}, \vec{\epsilon}_{i}, G^{*}(\vec{B}, c)\right) \\
& \equiv \tilde{u}\left(s_{i}, r_{i}, \vec{B}, c\right)+\epsilon_{i s_{i}},
\end{aligned}
$$


where $\tilde{u}$ is recursively written as a function of the state at the current period.

Dropping the time subscript, we let $V\left(r_{i}, \vec{\epsilon}_{i}, \vec{B}, c\right)$ denote the value to consumer $i$ when she is in state $\left(r_{i}, \vec{\epsilon}_{i}, \vec{B}, c\right)$. The Bellman equation that characterizes consumer $i$ 's value function if firms and all other consumers behave according to the MPE is

$$
\begin{aligned}
& V\left(r_{i}, \vec{\epsilon}_{i}, \vec{B}, c\right) \\
& \quad=\max _{s_{i}}\left[\tilde{u}\left(s_{i}, r_{i}, \vec{B}, c\right)+\epsilon_{i s_{i}}+\beta_{2} E_{r_{i}^{\prime}, \vec{\epsilon}_{i}^{\prime}, c^{\prime}} V\left(r_{i}^{\prime}, \vec{\epsilon}_{i}^{\prime}, \vec{B}^{\prime}, c^{\prime}\right)\right],
\end{aligned}
$$

where $\beta_{2}$ is the consumers' discount factor, $r_{i}^{\prime}=d\left(s_{i}\right), \vec{B}^{\prime}=$ $H^{*}(\vec{B}, c)$, and the expectation on the right-hand side is taken over $r_{i}^{\prime}, \vec{\epsilon}_{i}^{\prime}$, and $c^{\prime} .{ }^{10}$ We reserve $\beta_{1}$ to denote the firms' discount factor. Because there is a continuum of consumers, an individual consumer's choice will not affect current prices or the transition of the aggregate state. Therefore, from an individual consumer's point of view, as long as firms and all other consumers behave according to the MPE, current prices as a function of the state will be $G^{*}(\vec{B}, c)$ and the next-period's state will be $H^{*}(\vec{B}, c)$, regardless of her own choice.

The consumer's policy function associated with the above Bellman equation can be written as

$s_{i}=s^{*}\left(r_{i}, \vec{\epsilon}_{i}, \vec{B}, c\right)$.

Define $\tilde{V}\left(r_{i}, \vec{B}, c\right) \equiv E_{\vec{\epsilon}_{i}} V\left(r_{i}, \vec{\epsilon}_{i}, \vec{B}, c\right)$ to be the expected value function, where the expectation is taken over the idiosyncratic shocks $\vec{\epsilon}$. Then $\tilde{V}(\cdot)$ is given by

$$
\begin{aligned}
\tilde{V}\left(r_{i}, \vec{B}, c\right)= & E_{\vec{\epsilon}}\left\{\operatorname { m a x } _ { s _ { i } } \left[\tilde{u}\left(s_{i}, r_{i}, \vec{B}, c\right)+\epsilon_{i s_{i}}\right.\right. \\
& \left.\left.+\beta_{2} E_{r_{i}^{\prime}, c^{\prime}} \tilde{V}\left(r_{i}^{\prime}, H^{*}(\vec{B}, c), c^{\prime}\right)\right]\right\} .
\end{aligned}
$$

Further assume that $\epsilon_{i j t}$ is distributed type 1 extreme value, independent across consumers, goods, and time. Then, the equation above can be written as

$$
\begin{aligned}
\tilde{V}\left(r_{i}, \vec{B}, c\right)= & \log \left\{\sum _ { j = 0 } ^ { J } \operatorname { e x p } \left(\tilde{u}\left(j, r_{i}, \vec{B}, c\right)\right.\right. \\
& \left.\left.+\beta_{2} E_{r_{j}^{\prime}, c^{\prime}} \tilde{V}\left(r_{j}^{\prime}, H^{*}(\vec{B}, c), c^{\prime}\right)\right)\right\} .
\end{aligned}
$$

We will iterate over this functional equation to solve for the expected value function.

\subsection{Aggregate demand and supply functions}

Assume that the current price vector is $\vec{p}_{t}$ and that consumers anticipate the next-period's vector of used car stocks to be $\vec{B}_{t+1}$, which is a function of the current state, $\vec{B}_{t}$, and the current output choices by the firms and will be given by the aggregate state transition function. Consider the consumers who own a good

\footnotetext{
10 Because of the absence of transaction costs and the quasi-linearity assumption, the per-period utility in (5) can be expressed as:

$\tilde{u}\left(s_{i}, 0, \vec{B}, c\right)+\epsilon_{i s_{i}}+\gamma p_{r_{i}}$,

which implies that (7) can be written as:

$V\left(r_{i}, \vec{\epsilon}_{i}, \vec{B}, c\right)=V\left(0, \vec{\epsilon}_{i}, \vec{B}, c\right)+p_{r_{i}}$
}

indexed by $j^{\prime}$ at the beginning of period $t$. With the type 1 extremevalue assumption on idiosyncratic shocks, among such consumers, the proportion who choose good $j$ for consumption in period $t$ is given by

$$
\begin{aligned}
Q_{j}\left(j^{\prime}, \vec{p}_{t}, \vec{B}_{t+1}\right) & \\
= & \frac{\exp \left(\alpha_{j}+\gamma \cdot\left(p_{j^{\prime} t}-p_{j t}\right)+\beta_{2} E_{r_{j}^{\prime}, c_{t+1}} \tilde{V}\left(r_{j}^{\prime}, \vec{B}_{t+1}, c_{t+1}\right)\right)}{\sum_{k=0}^{J} \exp \left(\alpha_{k}+\gamma \cdot\left(p_{j^{\prime} t}-p_{k t}\right)+\beta_{2} E_{r_{k}^{\prime}, c_{t+1}} \tilde{V}\left(r_{k}^{\prime}, \vec{B}_{t+1}, c_{t+1}\right)\right)},
\end{aligned}
$$

where $\tilde{V}(\cdot)$ is a consumer's expected value function.

The quantity demanded of car $j$ in period $t$ satisfies

$$
\begin{aligned}
& q_{j}^{D}\left(\vec{p}_{t}, \vec{B}_{t+1}\right)=M \cdot \sum_{j^{\prime}=0,2, \ldots, J: j^{\prime} \neq j} K_{j^{\prime} t} \cdot Q_{j}\left(j^{\prime}, \vec{p}_{t}, \vec{B}_{t+1}\right), \\
& j=1, \ldots, J .
\end{aligned}
$$

The quantity demanded of car $j$ does not include the consumers who own car $j$ at the beginning of the period and who choose to keep their cars in that period. (Note that, without transaction costs, these consumers would be indifferent between keeping their car and trading it to repurchase it. Therefore, we could have assumed, instead, that all consumers transact in every period.)

Similarly, the quantity supplied of used car $j$ in period $t$ satisfies

$$
q_{j}^{S}\left(\vec{p}_{t}, \vec{B}_{t+1}\right)=M \cdot \sum_{j^{\prime}=0,1, \ldots, J: j^{\prime} \neq j} K_{j t} \cdot Q_{j^{\prime}}\left(j, \vec{p}_{t}, \vec{B}_{t+1}\right),
$$$$
j=2, \ldots, J \text {. }
$$

That is, the quantity supplied of used cars $j$ does not include the consumers who own car $j$ at the beginning of the period and who choose to keep it in that period.

Together with the firms' new car supply, the above functions will identify the inverse demand equations and form the basis for the market-clearing conditions in equilibrium.

\subsection{Firms' problem}

There are $N$ firms in the industry. They produce homogeneous new cars and engage in quantity competition. Let firms' equilibrium policy function be $q^{*}(\vec{B}, c)$, which is the same for all firms as we restrict our attention to symmetric MPE. Now consider firm $n$ 's problem. When choosing its quantity, firm $n$ presumes that consumers and all other firms behave according to the MPE. Hence, if it produces $q_{n t}$, its period- $t$ profit is

$\Pi\left(\vec{B}_{t}, c_{t}, q_{n t}, q_{-n t}^{*}\right)=q_{n t} \cdot\left(\widetilde{p}_{1 t}\left(\vec{B}_{t}, q_{n t}, q_{-n}^{*}\left(\vec{B}_{t}, c_{t}\right)\right)-c_{t}\right)$,

where $q_{-n}^{*}\left(\vec{B}_{t}, c_{t}\right)$ indicates that all of firm $n$ 's rivals choose $q^{*}\left(\vec{B}_{t}, c_{t}\right)$, and $\widetilde{p}_{1 t}\left(\vec{B}_{t}, c_{t}, q_{n t}, q_{-n}^{*}\left(\vec{B}_{t}, c_{t}\right)\right)$ is the first element in $\overrightarrow{\widetilde{p}}_{t}\left(\vec{B}_{t}, c_{t}, q_{n t}, q_{-n}^{*}\left(\vec{B}_{t}, c_{t}\right)\right)$, which is the inverse demand function and is part of $\left(\overrightarrow{\widetilde{p}}_{t}\left(\vec{B}_{t}, c_{t}, q_{n t}, q_{-n}^{*}\left(\vec{B}_{t}, c_{t}\right)\right), \overrightarrow{\widetilde{B}}_{t+1}\left(\vec{B}_{t}, c_{t}, q_{n t}\right.\right.$, $\left.\left.q_{-n}^{*}\left(\vec{B}_{t}, c_{t}\right)\right)\right)$ and is the solution to the system of equations given by the aggregate state transition functions and the market-clearing conditions

$$
\left\{\begin{array}{l}
K_{2 t+1}=\left(q_{n t}+(N-1) q_{-n}^{*}\left(\vec{B}_{t}, c_{t}\right)\right) / M+(1-\delta) K_{2 t}, \\
K_{j t+1}=\delta K_{j-1 t}+(1-\delta) K_{j t}, j=3, \ldots, J, \\
q_{1}^{D}\left(\vec{p}_{t}, \vec{B}_{t+1}\right)=q_{n t}+(N-1) q_{-n}^{*}\left(\vec{B}_{t}, c_{t}\right), \\
q_{j}^{D}\left(\vec{p}_{t}, \vec{B}_{t+1}\right)=q_{j}^{S}\left(\vec{p}_{t}, \vec{B}_{t+1}\right), j=2, \ldots, J .
\end{array}\right.
$$

In this system, there are $2 J-1$ equations and $2 J-1$ unknowns. The equations are the $J-1$ aggregate state transitions for the used 
cars and the $J$ market-clearing conditions. The unknowns are the $J-1$ next-period used car stocks and the $J$ current prices. ${ }^{11}$

The Bellman equation that characterizes firm $n$ 's value function given that all other firms and all consumers behave according to the MPE is

$W(\vec{B}, c)=\max _{q_{n}}\left[\Pi\left(\vec{B}, c, q_{n}, q_{-n}^{*}\right)+\beta_{1} E_{c^{\prime}} W\left(\vec{B}^{\prime}, c^{\prime}\right)\right]$,

where $\beta_{1}$ is the firms' discount factor, $\vec{B}^{\prime}=\overrightarrow{B^{\prime}}\left(\vec{B}, c, q_{n}, q_{-n}^{*}(\vec{B}, c)\right)$, and the expectation on the right-hand side is taken over $c^{\prime}$. In equilibrium, the previously conjectured aggregate state and price transition functions, $H^{*}(\cdot)$ and $G^{*}(\cdot)$, respectively, must satisfy: $H^{*}(\vec{B}, c)=\overrightarrow{\tilde{B}}^{\prime}\left(\vec{B}, c, q_{n}^{*}(\vec{B}, c), q_{-n}^{*}(\vec{B}, c)\right)$ and $G^{*}(\vec{B}, c)=$ $\overrightarrow{\tilde{p}}\left(\vec{B}, c, q_{n}^{*}(\vec{B}, c), q_{-n}^{*}(\vec{B}, c)\right)$.

\subsection{Equilibrium}

A Markov-perfect equilibrium in the model consists of the following functions: the price function $G^{*}(\vec{B}, c)$, the aggregate state transition function $H^{*}(\vec{B}, c)$, the firms' policy functions $q^{*}(\vec{B}, c)$, the firms' value functions $W^{*}(\vec{B}, c)$, and the consumers' expected value functions $\tilde{V}^{*}\left(r_{i}, \vec{B}, c\right)$, such that

1. Given $q^{*}(\vec{B}, c)$ for all firms and $\tilde{V}^{*}\left(r_{i}, \vec{B}, c\right)$ for all consumers, $G^{*}(\vec{B}, c)$ and $H^{*}(\vec{B}, c)$ solve the system of equations in (15).

2. Given $q^{*}(\vec{B}, c)$ for all other firms, $W^{*}(\vec{B}, c)$ applied to the next period, and $\tilde{V}^{*}\left(r_{i}, \vec{B}, c\right)$ for all consumers, $q^{*}(\vec{B}, c)$ is the solution to the maximization problem in (16).

3. Given $G^{*}(\vec{B}, c), H^{*}(\vec{B}, c)$, and $q^{*}(\vec{B}, c)$ for all firms, $W^{*}(\vec{B}, c)$ satisfies the firm's Bellman Eq. (16).

4. Given $G^{*}(\vec{B}, c)$ and $H^{*}(\vec{B}, c), \tilde{V} *\left(r_{i}, \vec{B}, c\right)$ satisfies the functional Eq. (10).

We employ the collocation method to solve for the equilibrium. We approximate the above functions using linear combinations of Chebyshev polynomials (Judd, 1998; Miranda and Fackler, 2002). For example, if the life of a car consists of two stages, so that $\vec{B}_{t}=K_{2 t}$, the firm's policy function $q^{*}(\cdot)$ is expressed as

$$
q^{*}\left(K_{2 t}, c_{t}\right) \approx \begin{cases}\sum_{i=0}^{n} \lambda_{1 i} \phi_{1 i}\left(K_{2 t}\right) & \text { if } c_{t}=\bar{c}-\tilde{c}, \\ \sum_{i=0}^{n} \lambda_{2 i} \phi_{2 i}\left(K_{2 t}\right) & \text { if } c_{t}=\bar{c}, \\ \sum_{i=0}^{n} \lambda_{3 i} \phi_{3 i}\left(K_{2 t}\right) & \text { if } c_{t}=\bar{c}+\tilde{c},\end{cases}
$$

where for $m=1,2,3, \phi_{m i}\left(K_{2 t}\right)$ is an ith-order Chebyshev polynomial in $K_{2 t}, \lambda_{m}=\left(\lambda_{m i}\right)_{i=0, \ldots, n}$ is a vector of $n+1$ unknown coefficients, and $n$ is the order of the approximation. The expressions for $G^{*}(\cdot), H^{*}(\cdot), W^{*}(\cdot)$, and $\tilde{V}^{*}(\cdot)$ are obtained analogously. With the collocation method, the above functions are evaluated at the pre-specified collocation points to check for the equilibrium conditions.

We restrict attention to symmetric MPE and use an iterative algorithm to compute the equilibrium. ${ }^{12}$ The algorithm takes the

\footnotetext{
11 Alternatively, one could first obtain the $J-1$ next-period used car stocks using the $J-1$ aggregate state transitions, and then plug these next-period used car stocks into the $J$ market-clearing conditions, so that there are $J$ unknown prices and $J$ market-clearing conditions.

12 While uniqueness cannot in general be guaranteed, our algorithm always converges and results in a unique equilibrium, irrespective of the starting point and the particulars of the algorithm.
}

firm's policy function $q^{0}(\cdot)$, the firm's value function $W^{0}(\cdot)$, and the consumer's expected value function $\tilde{V}^{0}(\cdot)$ as its input and generates updated functions $q^{1}(\cdot), W^{1}(\cdot)$, and $\tilde{V}^{1}(\cdot)$ as its output. Each iteration proceeds as follows. We first obtain $q^{1}(\cdot)$ by solving the maximization problem on the right-hand side of (16), taking $W^{0}(\cdot)$ and $\tilde{V}^{0}(\cdot)$ as given and assuming all other firms follow $q^{0}(\cdot)$. This step also produces the price function $G^{1}(\cdot)$ and the aggregate state transition function $H^{1}(\cdot)$. We next obtain $W^{1}(\cdot)$, according to (16), taking $q^{1}(\cdot), G^{1}(\cdot)$, and $H^{1}(\cdot)$ as given. We then solve for $\tilde{V}^{1}(\cdot)$ by iterating over the functional equation in (10), taking $q^{1}(\cdot), G^{1}(\cdot)$, and $H^{1}(\cdot)$ as given. The iteration is completed by assigning $q^{1}(\cdot)$ to $q^{0}(\cdot), W^{1}(\cdot)$ to $W^{0}(\cdot)$, and $\tilde{V}^{1}(\cdot)$ to $\tilde{V}^{0}(\cdot)$. The iterative algorithm terminates once the relative changes in the policy and value functions from one iteration to the next are below a pre-specified tolerance. The equilibrium $G^{*}(\cdot)$ and $H^{*}(\cdot)$ are then obtained by solving the system of equations in (15) once more, taking the equilibrium $q^{*}(\cdot), W^{*}(\cdot)$, and $\tilde{V}^{*}(\cdot)$ as given.

\section{Parameterization}

Here we present the parameter values that are used in our baseline model. We normalize the population of consumers $M$ to be 1 . We assume that the life of a car consists of 2 stages, new and used, and that used cars die stochastically. We consider an oligopoly with $N=3 .^{13}$

We assume the interest rate to be $4 \%$, which is common for consumers and firms. This gives discount factors $\beta_{1}=\beta_{2}=$ $1 / 1.04 \approx 0.96$. The depreciation parameter $\delta$ is chosen to match the average age of cars in the US data. The 2001 National Household Travel Survey (NHTS) reports that the average automobile age in the United States was 9 years. In our model, this translates into a depreciate rate of $\delta=0.11$.

We choose $\bar{c}$, the constant component in the marginal cost of production, to equal the estimate of marginal cost (after deflating it) in Copeland et al. (2005) (page 28). There a marginal cost of $\$$ 17,693 (in 2000 dollars) is reported, which corresponds to $\$ 18,905$ in 2003 dollars, so we set $\bar{c}=\$ 19,000 .{ }^{14}$ We let $\tilde{c}$, the magnitude of the industry-wide cost shocks, equal $0.1 \times \bar{c}=\$ 1900$. The cost shock probability $\rho$ is set at 0.1 .

We follow Chen et al. (2007) in choosing $\alpha_{1}$ (the new car utility), $\alpha_{2}$ (the used car utility), and $\gamma$ (the consumers' marginal utility of money). The calibration exercise in that paper, which is based on the American automobile industry over the 1994-2003 period, finds that $\alpha_{1}=2.07$ and $\alpha_{2}=1.40$. In that paper there are two types of consumers in equal proportions, with marginal utilities of money calibrated to be 1.86 and 2.75, respectively. Here we set $\gamma$ to be 2.31, which is the average of the two numbers. Table 1 reports the simulated steady state quantities and prices and the US market averages over the 1994-2003 period.

Table 2 summarizes the parameter values that are used in our baseline model. The equilibrium new car production per firm, the

\footnotetext{
13 In the car industry, as in many other durable goods industries, firms do not have monopoly power and the oligopolistic setting is more appropriate. We also vary the number of firms and the results are robust.

${ }^{14}$ An alternative would be to use the marginal cost estimates in Berry et al. (1995) (page 882), but recent estimates are significantly lower reflecting the reduction in marginal costs of production in the industry over more recent years.
} 
Table 1

Steady-state quantities and prices at calibrated parameter values

\begin{tabular}{|c|c|c|}
\hline & Model steady state values & US data averages (1994-2003) \\
\hline $\begin{array}{l}\text { New vehicle sales } \\
\text { and leases }\end{array}$ & 0.07 & 0.08 \\
\hline $\begin{array}{l}\text { Used vehicle sales } \\
\text { and leases }\end{array}$ & 0.22 & 0.20 \\
\hline New vehicle price & $\$ 22,800$ & $\$ 23,000$ \\
\hline Used vehicle price & $\$ 9500$ & $\$ 9000$ \\
\hline
\end{tabular}

Table 2

Baselline parameterization

$M$ (consumer population)

$J$ (number of stages in the life of a car)

Discount factor $\left(\beta_{1}\right.$ and $\left.\beta_{2}\right)$

Probability of used car depreciation $(\delta)$

Constant component in marginal costs $(\bar{c})$

Magnitude of cost shocks $(\tilde{c})$

Cost shock probability $(\rho)$

Number of firms

New car utility $\left(\alpha_{1}\right)$

Used car utility $\left(\alpha_{2}\right)$

Consumers' marginal utility of money $(\gamma)$

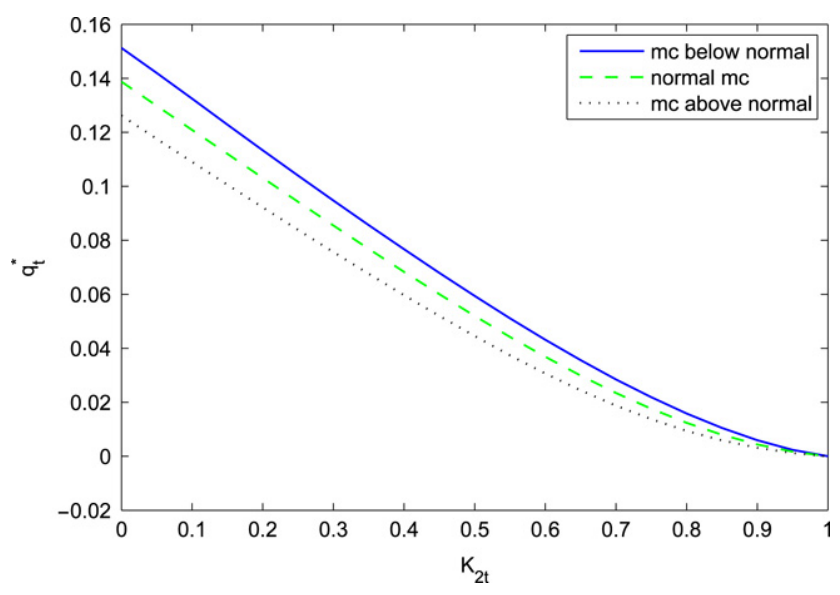

Fig. 1. Firm production, baseline model.

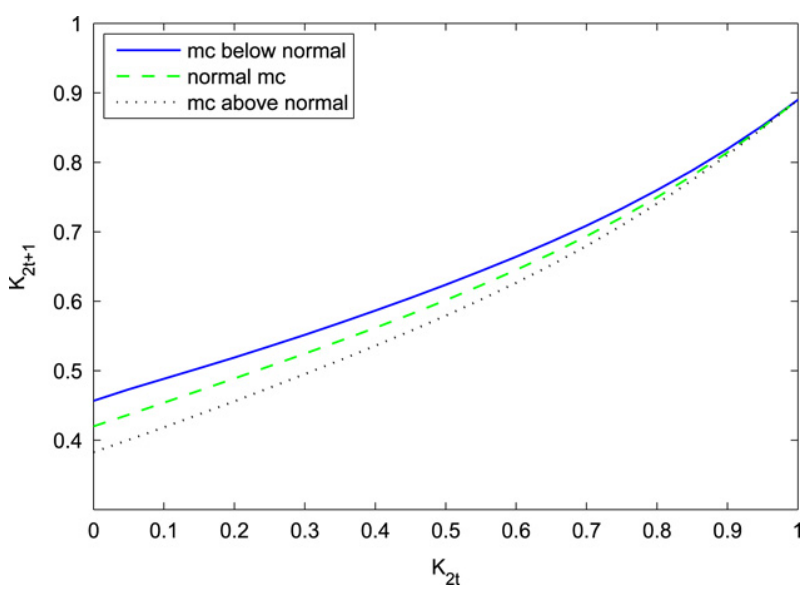

Fig. 2. State transition, baseline model.

state transition, the new car price, and the firms' payoff for the baseline parameterization are presented in Figs. 1-4, respectively, as functions of the industry state. If a period starts with more consumers owning used cars, we expect the demand for new cars to be weaker and the firms' profitability to be lower. This intuition is confirmed by the figures, which show that a larger $K_{2 t}$ leads to lower new car production, lower new car price, and lower firms'

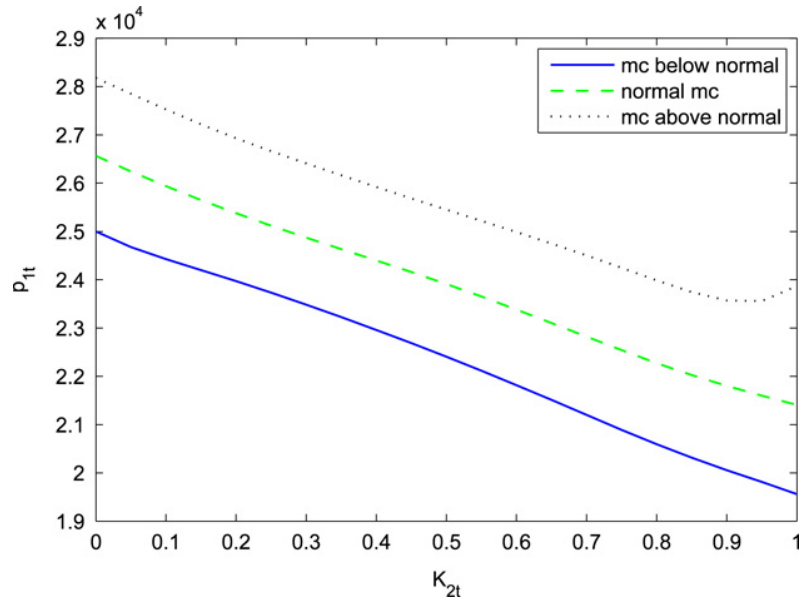

Fig. 3. New car price, baseline model.

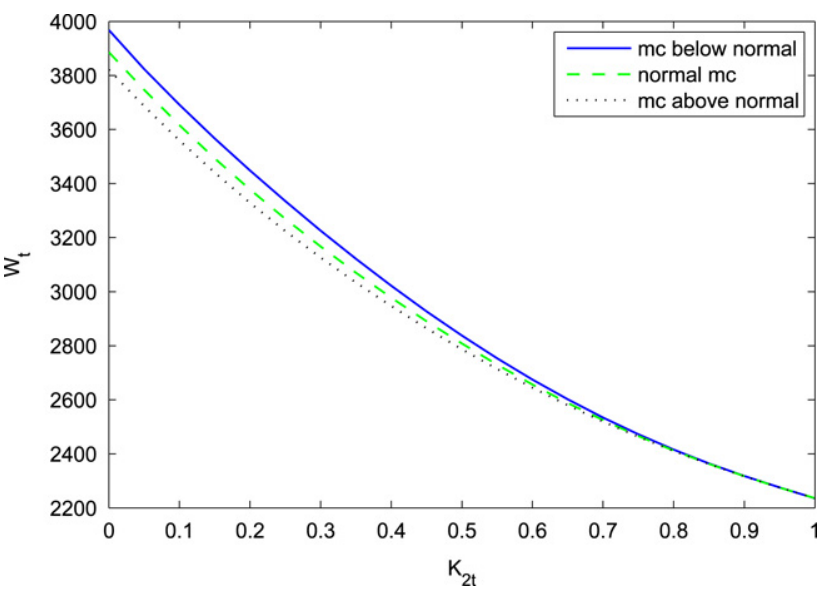

Fig. 4. Firm payoff, baseline model.

payoff. Also note that when the marginal cost of production is below normal (that is, $c=\bar{c}-\tilde{c}$ ), the new car production is higher than normal, the new car price is lower than normal, and the firms' payoff is higher than normal. The opposite is true when the marginal cost of production is above normal (that is, $c=\bar{c}+\tilde{c}$ ).

\section{Estimation bias}

Our model contains dynamics on both sides of the market. If one estimates an industry with such dynamics using a misspecified static model, the results will be biased. There are two aspects to this bias. One involves the measurement of the price elasticity of demand, which is incorrectly measured because of estimating a static demand model. Properly accounting for dynamic demand in estimating the price elasticities has also been done in other papers. The second aspect is that, even if the elasticity is measured correctly, the firms' markup will be mis-measured if the supply-side first-order conditions used to infer the markup are derived from a static model rather than a dynamic model. To our knowledge, this aspect of the bias has not been addressed in the existing literature.

In this section, we first simulate quantity and price data using our dynamic durable-goods model. Next we use the simulated data to estimate price elasticities of demand and firms' markups. We then compare these estimates to the model's true values and compute the biases. At the end of the section, we perform robustness checks.

For each of the parameterizations considered, we let the industry evolve $T=10000$ periods according to the equilibrium 
of the model, and obtain simulated quantity and price data for these periods. The simulated dataset is a panel dataset consisting of repeated observations on the same two products (new cars and used cars) over time. For each period, an i.i.d. cost shock (or cost shifter) is generated based on (3). One example of such a cost shifter in the car industry would be wages of automobile workers. The researcher performing the static estimation observes the sequence of cost shifters and uses them as an instrumental variable (IV) to address the endogeneity problem in demand estimation due to the correlation of prices with unobserved product quality. In a static setting, the cost shocks would be an appropriate instrument (as in Berry (1994)). However, as we will show below, in a dynamic setting, these cost shocks no longer satisfy the IV assumptions.

\subsection{Price elasticity of demand}

In this subsection, we calculate the price elasticity for new cars, first according to the dynamic model, then using the static estimation method. In both cases, the elasticity is evaluated at $\widehat{Q}$, the average industry new car production in the simulated data. We then quantify the bias.

\subsubsection{Elasticities in the dynamic model}

In the dynamic model, the price elasticity of demand for new cars is obtained numerically based on the system of equations that characterizes current prices and the next period's state as a function of the used car stock $K_{2}$ and the new car production $Q_{\text {. }}$ Let $\widehat{K}_{2}$ denote the used car stock that induces each firm to produce $\widehat{Q} / N$ when the cost shock equals zero; that is, $\widehat{K}_{2}$ satisfies $q^{*}\left(\widehat{K}_{2}, \bar{c}\right)=$ $\widehat{Q} / N$. The elasticity is given by

$e=\frac{\widetilde{p}_{1}}{\widehat{Q}} / \frac{\partial \widetilde{p}_{1}}{\partial \widehat{Q}}$,

where $\widetilde{p}_{1}$ is the first element in $\widetilde{\vec{p}}\left(\widehat{K}_{2}, \widehat{Q}\right)$, which is a component of the solution to the system of equations given by the aggregate state transition function and the market-clearing conditions

$$
\left\{\begin{array}{l}
K_{2}^{\prime}=\widehat{Q} / M+(1-\delta) \widehat{K}_{2}, \\
q_{1}^{D}\left(\vec{p}, K_{2}^{\prime}\right)=\widehat{Q}, \\
q_{2}^{D}\left(\vec{p}, K_{2}^{\prime}\right)=q_{2}^{S}\left(\vec{p}, K_{2}^{\prime}\right) .
\end{array}\right.
$$

It is clear from the above system of equations that when the new car production changes, not only does the new car price change in response, but the used car price also has to change. Given a different level of new car production, if the used car price is held fixed, then at least one of the equations in the system will not be satisfied.

To illustrate this point, we construct an alternative "naive" elasticity measure, denoted $\eta$, that corresponds to the case when the used car price is held fixed and the market-clearing condition for the secondary market is not imposed

$\eta=\frac{\widetilde{\tilde{p}}_{1}}{\widehat{Q}} / \frac{\partial \widetilde{\tilde{p}}_{1}}{\partial \widehat{Q}}$,

where $\widetilde{\widetilde{p}}_{1}$ is the new car price which satisfies the reduced system of equations

$$
\left\{\begin{array}{l}
K_{2}^{\prime}=\widehat{Q} / M+(1-\delta) \widehat{K}_{2}, \\
q_{1}^{D}\left(p_{1}, \widetilde{p}_{2}, K_{2}^{\prime}\right)=\widehat{Q} .
\end{array}\right.
$$

In these equations, $\widetilde{p}_{2}$ is fixed at the value which solve Eq. (10) and not allowed to adjust as $Q$ is varied in order to calculate the elasticity. This naive elasticity measure $\eta$ fails to recognize the effect that new car production has on used car prices.

\subsubsection{Elasticities estimated using static model}

From the viewpoint of the researcher performing the static estimation, the utility of consumer $i$ for product $j$ in period $t$ is given by

$$
\begin{aligned}
u_{i j t} & =\mathbf{w}_{j} \boldsymbol{\alpha}-\gamma p_{j t}+\xi_{j t}+\epsilon_{i j t} \\
& =\alpha_{1} \text { new }_{j}+\alpha_{2} \text { used }_{j}-\gamma p_{j t}+\xi_{j t}+\epsilon_{i j t},
\end{aligned}
$$

where (1) $j=0,1,2$ denote the outside good, new cars, and used cars, respectively; (2) $\mathbf{w}_{j}$ are observed product characteristics, which consist of two dummies: the new car dummy new $w_{j}$ and the used car dummy used $_{j}$, with new $w_{1}=$ used $_{2}=1$ and new $w_{2}=$ used $_{1}=$ new $_{0}=$ used $_{0}=0$; (3) $p_{j t}$ is the price of product $j$ in period $t$, with $p_{0 t}=0$, for all $t$; (4) $\xi_{j t}$ is the unobserved (by the researcher) product quality in period $t$; and, (5) the consumers' idiosyncratic shocks $\epsilon_{i j t}$ are distributed i.i.d. type 1 extreme value. In the static model, consumers choose the product which yields the highest static utility:

consumer $i$ chooses product $j \Leftrightarrow u_{i j t}=\max _{j^{\prime}} u_{i j^{\prime} t}$.

With the type 1 extreme-value assumption on the idiosyncratic shocks, we can follow Berry (1994) to derive the estimating equations for the market shares, which are

$$
\begin{aligned}
y_{j t} & \equiv \ln \left(q_{j t}\right)-\ln \left(q_{0 t}\right) \\
& =\mathbf{w}_{j} \boldsymbol{\alpha}-\gamma p_{j t}+\xi_{j t} \equiv \mathbf{x}_{j t} \boldsymbol{\theta}+\xi_{j t},
\end{aligned}
$$

where $y_{j t}$ is the mean utility level of product $j$ in period $t, q_{j t}$ is product $j$ 's observed market share in period $t$ (recall that the consumer population is normalized to 1$), \mathbf{x}_{j t}=\left(\right.$ new $_{j}$, used $\left._{j}, p_{j t}\right)$, $\boldsymbol{\theta}=\left(\alpha_{1}, \alpha_{2},-\gamma\right)$, and the mean utility level of the outside good is normalized to zero.

The researcher has a panel data set that consists of repeated observations of market shares and prices on the same two products (new cars and used cars) over time. He observes the cost shocks $v_{t}$ and uses them as an instrumental variable (IV) to address the endogeneity problem in demand estimation due to the correlation of prices $p_{j t}$ with unobserved product quality $\xi_{j t}$.

In the framework of the static model, $v_{t}$ is correlated with both the new car price and the used car price, but uncorrelated with the unobserved product quality $\xi_{j t}$. Hence, it is valid as an instrument for price. Therefore, the researcher estimates the static model using the system 2SLS estimator, with instruments vectors $\mathbf{z}_{1 t}=\mathbf{z}_{2 t}=$ $\left(\right.$ new $_{j}$, used $\left._{j}, v_{t}\right)$, under the assumption that $E\left(\mathbf{z}_{j t}^{\prime} \xi_{j t}\right)=\mathbf{0}$ for $j=$ 1,2 and $t=1,2, \ldots, T$. In this case, the system 2SLS estimator is a pooled 2SLS estimator, that is, it is the estimator obtained by 2SLS estimation of (24) using instruments $\mathbf{z}_{j t}$, which are pooled across all $j$ and $t .{ }^{15}$ Denote this estimator by $\widehat{\boldsymbol{\theta}}=\left(\widehat{\alpha}_{1}, \widehat{\alpha}_{2},-\widehat{\gamma}\right)$.

Using the elasticity formula for the logit case (page 63 in Train (2003)), the static estimate of the price elasticity of demand for new cars is then obtained as

$\widehat{e}=-\widehat{\gamma} \widehat{p}_{1}(1-\widehat{Q})$,

where $\widehat{p}_{1}$ and $\widehat{Q}$ are, respectively, the average new car price and the average industry new car production in the simulated data.

15 See pages 206-207 in Wooldridge (2002). 


\subsubsection{Bias in static elasticity estimates}

The bias in the static estimate of the price elasticity of demand for new cars comes from two sources.

First, if the researcher assumes the static choice model (23), but the true model is dynamic, then a missing variable in the utility specification (22) is the expected discounted value function $\beta_{2} E_{d(j), c_{t+1}} \tilde{V}^{*}\left(d(j), H^{*}\left(\vec{B}_{t}, c_{t}\right), c_{t+1}\right)$. Since the period $t$ cost shock $c_{t}$ is correlated with $H^{*}\left(\vec{B}_{t}, c_{t}\right)$ (i.e., the next-period state), we know that $c_{t}$ is correlated with $\xi_{j t}$ (i.e., the expected future value of holding car $j$ in period $t$ ), as long as $\beta_{2}>0$, that is, as long as consumers are forward-looking. Since $v_{t}$ is a cost shifter and is correlated with $c_{t}$, the assumption that $E\left(v_{t} \xi_{j t}\right)=0$ is violated, and $v_{t}$ is no longer an appropriate instrument for prices. The bias in $\widehat{\gamma}$ then gives rise to bias in $\widehat{e}$. This first type of bias arises from ignoring the possibility that consumers in durable-goods markets are forward-looking.

Second, the estimate $\widehat{e}$ is obtained under the assumption that the used car price is held fixed even when the new car production varies. But in the dynamic model, given a level of new car production, the triplet $\left(p_{1}, p_{2}, K^{2 \prime}\right)$ is jointly determined according to the system of Eq. (19), so that the used car price necessarily changes when new car production changes. When new car production increases, the resulting decrease in used car price creates stronger competition for new cars, thus shifting the demand curve for new cars inward and causing a larger drop in new car prices. Consequently, the true price elasticity of new car demand is smaller than it would be if used car price were held fixed. The static estimation fails to recognize this factor, and so it overestimates (in absolute terms) the demand elasticity. Note that this bias is present even when $\beta_{2}=0$, and $c_{t}$ is a valid instrument orthogonal to $\xi_{t}$. This second type of bias arises from ignoring the possibility that firms in durable-goods markets are forward-looking.

Since the severity of the two types of biases should depend on how much firms and consumers discount the future, we quantify the biases in three sets of counterfactuals which vary $\beta_{1}$ (the firms' discount factor) and $\beta_{2}$ (consumers' discount factor). These counterfactuals are:

Counterfactual A: $\beta_{1}$ fixed at $1 / 1.04 ; \beta_{2}$ lowered from $1 / 1.04$ to 0

Counterfactual B: $\beta_{2}$ fixed at $0 ; \beta_{1}$ lowered from $1 / 1.04$ to 0

Counterfactual C: both $\left(\beta_{1}, \beta_{2}\right)$ lowered from $1 / 1.04$ to 0

For each set of counterfactuals, we computed: (i) the price coefficient $\gamma$; (ii) the estimated static elasticity $e^{\wedge}$ using Eq. (25); (iii) the true dynamic elasticity e using Eq. (18); and (iv) the naive elasticity using Eq. (20). Note that the latter two quantities are not estimated using the simulated data, but rather computed at the assumed parameter values.

Results for these three sets of counterfactuals are reported in Tables 3-5. Also reported are the biases in the estimates, each calculated as the difference between the estimate and the true value, divided by the absolute value of the latter. The results support our discussion above regarding the two types of biases and their sources.

First, the price coefficient $\widehat{\gamma}$ is estimated with bias, as shown in Tables 3 and 5 . The percentage biases are small, equal to just $2.1 \%$ in both Counterfactuals A (Table 3 ) and C (Table 5). Only in Counterfactual B (Table 4), where $\beta_{2}=0$ (so that consumers are not forward-looking), is the bias equal to zero. Hence, the biases in $\hat{\gamma}$ represent the first type of bias, which arises from ignoring the possibility that consumers are forward-looking.

Second, across all three counterfactuals, the naive elasticity $\eta$ is larger (in absolute value) than $e$. Since the difference between $\eta$ and $e$ arises from ignoring the intertemporal feedback between new and used car prices, this finding confirms that ignoring this feedback leads to overestimation of the demand elasticity. The percentage differences between $\eta$ and $e$ range from $-2 \%$ to $-47 \%$, with the largest coming from the baseline parameterization (in Table 3). Moreover, as we expect, this overestimation is more pronounced when $\beta_{1}$ or $\beta_{2}$ is larger, which shows that ignoring forward-looking behavior can lead to wrong conclusions that the demand curve for new cars is relatively elastic.

Third, we see that $\hat{e}$, the estimated static demand elasticity, reflects both types of bias. In Table 4 , we see that when $\beta_{2}$ is fixed at zero, which eliminates the first source of bias, $\widehat{e}$ is exactly the same as $\eta$. However, even in this case, $\widehat{e}$ is still biased from the true dynamic elasticity $e$, due to the second source of bias. In particular, we see that $\widehat{e}$ is an overestimate of $e$, in absolute terms. The percentage biases in $\widehat{e}$ range from $-2 \%$ to $-68 \%$, again with the largest coming from the baseline parameterization.

These results show clearly that ignoring the dynamics in durable-goods markets leads to estimates which indicate a more elastic demand curve. Next, we see that these biased elasticities lead to downward-biased markup measures, and to a mistaken conclusion that these markets are more competitive than they actually are.

\subsection{Effects on markups}

For our analysis of biases in markup estimates, we first introduce a benchmark measure of "true" markups for the dynamic model:

$\kappa=\left(\widehat{p}_{1}-\widehat{c}\right) / \widehat{p}_{1}$,

where $\widehat{p}_{1}$ and $\widehat{c}$ are the average of new car price and the average of marginal cost in the simulated data, respectively.

In what follows, we derive an estimate of firms' markups $\hat{\kappa}$ using $\hat{e}$, the static estimate of demand elasticity, and then quantify the bias $\hat{\kappa}-\kappa$.

\subsubsection{Markups estimated using static model}

Since the researcher does not observe $\widehat{c}$, he infers $\kappa$ using $\hat{e}$, his static estimate of the price elasticity of demand for new cars. Specifically, because the researcher wrongly uses a static model, while ignores firms' forward-looking behavior, he mistakenly models firm $n$ 's profits as

$p i_{n}=q_{n}\left(p_{1}(Q)-c\right)$,

where $q_{n}$ is firm $n$ 's new car production, and $Q$ is the industry's new car production. Using the Lerner's index, the first-order condition (FOC) resulting from this Cournot profit function is expressed as

$$
\frac{p_{1}-c}{p_{1}}=-\frac{1}{N} / e,
$$

where $1 / N$ is firm $n$ 's market share due to symmetry, and $e$ is the price elasticity of demand for new cars. The estimate that the researcher has for this elasticity is $\widehat{e}$, so he obtains a static estimate of the markup as

$\widehat{\kappa}=-\frac{1}{N} / \widehat{e}$. 
Table 3

Bias in elasticity and markup estimates - Baseline model, lowering $\beta_{2}$.

\begin{tabular}{|c|c|c|c|c|c|c|c|c|c|c|c|c|c|c|c|c|c|}
\hline $\mathrm{N}$ & $\delta$ & $\rho$ & $\beta_{1}$ & $\beta_{2}$ & $\gamma$ & $\hat{\gamma}$ & Bias (\%) & e & $\eta$ & Bias (\%) & $\hat{e}$ & Bias (\%) & $\kappa$ & $\hat{\kappa}$ & Bias (\%) & $\tilde{\kappa}$ & Bias (\%) \\
\hline 3 & 0.11 & 0.10 & 0.96 & 0.96 & 2.31 & 2.26 & -2.1 & -2.85 & -4.19 & -47 & -4.79 & -68 & 0.170 & 0.070 & -59 & 0.117 & -31 \\
\hline 3 & 0.11 & 0.10 & 0.96 & 0.80 & 2.31 & 2.29 & -0.7 & -3.16 & -4.20 & -33 & -4.75 & -51 & 0.147 & 0.070 & -52 & 0.106 & -28 \\
\hline 3 & 0.11 & 0.10 & 0.96 & 0.60 & 2.31 & 2.34 & 1.1 & -3.56 & -4.28 & -20 & -4.74 & -33 & 0.123 & 0.070 & -43 & 0.094 & -24 \\
\hline 3 & 0.11 & 0.10 & 0.96 & 0.40 & 2.31 & 2.30 & -0.4 & -3.95 & -4.38 & -11 & -4.61 & -17 & 0.105 & 0.072 & -31 & 0.084 & -19 \\
\hline 3 & 0.11 & 0.10 & 0.96 & 0.20 & 2.31 & 2.30 & -0.3 & -4.26 & -4.50 & -6 & -4.60 & -8 & 0.094 & 0.073 & -23 & 0.078 & -16 \\
\hline 3 & 0.11 & 0.10 & 0.96 & 0.00 & 2.31 & 2.31 & 0.0 & -4.49 & -4.60 & -2 & -4.60 & -2 & 0.083 & 0.073 & -13 & 0.074 & -11 \\
\hline
\end{tabular}

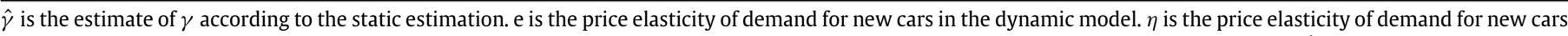

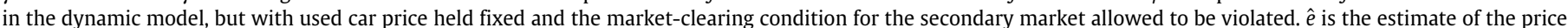

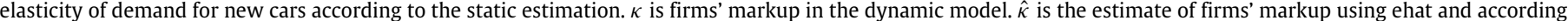
to Lerner's index. $\tilde{\kappa}$ is the estimate of firms' markup using e and according to Lerner's index. Bias is calculated as (estimate - truevalue) / | true value |.

Table 4

Bias in elasticity and markup estimates - Baseline model, setting $\beta_{2}=0$ and lowering $\beta_{1}$.

\begin{tabular}{|c|c|c|c|c|c|c|c|c|c|c|c|c|c|c|c|c|c|}
\hline $\mathrm{N}$ & $\delta$ & $\rho$ & $\beta_{1}$ & $\beta_{2}$ & $\gamma$ & $\hat{\gamma}$ & Bias (\%) & $\mathrm{e}$ & $\eta$ & Bias (\%) & $\hat{e}$ & Bias (\%) & $\kappa$ & $\hat{\kappa}$ & Bias (\%) & $\tilde{\kappa}$ & Bias (\%) \\
\hline 3 & 0.11 & 0.10 & 0.96 & 0.00 & 2.31 & 2.31 & 0.0 & -4.49 & -4.59 & -2 & -4.59 & -2 & 0.083 & 0.073 & -13 & 0.074 & -11 \\
\hline 3 & 0.11 & 0.10 & 0.80 & 0.00 & 2.31 & 2.31 & 0.0 & -4.47 & -4.57 & -2 & -4.57 & -2 & 0.079 & 0.073 & -8 & 0.075 & -6 \\
\hline 3 & 0.11 & 0.10 & 0.60 & 0.00 & 2.31 & 2.31 & 0.0 & -4.46 & -4.56 & -2 & -4.56 & -2 & 0.078 & 0.073 & -6 & 0.075 & -4 \\
\hline 3 & 0.11 & 0.10 & 0.40 & 0.00 & 2.31 & 2.31 & 0.0 & -4.45 & -4.56 & -2 & -4.56 & -2 & 0.077 & 0.073 & -5 & 0.075 & -2 \\
\hline 3 & 0.11 & 0.10 & 0.20 & 0.00 & 2.31 & 2.31 & 0.0 & -4.45 & -4.56 & -2 & -4.56 & -2 & 0.076 & 0.073 & -4 & 0.075 & -1 \\
\hline 3 & 0.11 & 0.10 & 0.00 & 0.00 & 2.31 & 2.31 & 0.0 & -4.45 & -4.55 & -2 & -4.55 & -2 & 0.075 & 0.073 & -3 & 0.075 & 0 \\
\hline
\end{tabular}

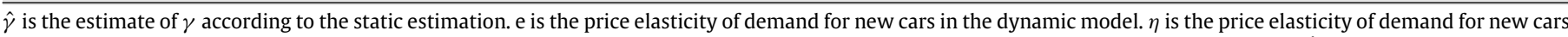

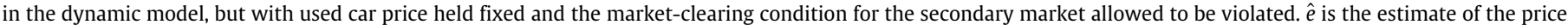

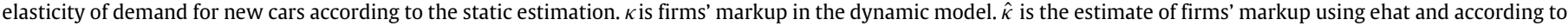
Lerner's index. $\tilde{\kappa}$ is the estimate of firms' markup using e and according to Lerner's index. Bias is calculated as (estimate - truevalue)/ |true value|.

Table 5

Bias in elasticity and markup estimates - Baseline model, lowering $\beta_{1}$ and $\beta_{2}$.

\begin{tabular}{|c|c|c|c|c|c|c|c|c|c|c|c|c|c|c|c|c|c|}
\hline $\mathrm{N}$ & $\delta$ & $\rho$ & $\beta_{1}$ & $\beta_{2}$ & $\gamma$ & $\hat{\gamma}$ & Bias (\%) & $\mathrm{e}$ & $\eta$ & Bias (\%) & $\hat{e}$ & Bias (\%) & $\kappa$ & $\hat{\kappa}$ & Bias (\%) & $\tilde{\kappa}$ & Bias (\%) \\
\hline 3 & 0.11 & 0.10 & 0.96 & 0.96 & 2.31 & 2.26 & -2.1 & -2.85 & -4.19 & -47 & -4.79 & -68 & 0.170 & 0.070 & -59 & 0.117 & -31 \\
\hline 3 & 0.11 & 0.10 & 0.80 & 0.80 & 2.31 & 2.29 & -0.7 & -3.10 & -4.14 & -34 & -4.68 & -51 & 0.135 & 0.071 & -47 & 0.108 & -20 \\
\hline 3 & 0.11 & 0.10 & 0.60 & 0.60 & 2.31 & 2.34 & 1.1 & -3.47 & -4.19 & -21 & -4.64 & -34 & 0.106 & 0.072 & -32 & 0.096 & -10 \\
\hline 3 & 0.11 & 0.10 & 0.40 & 0.40 & 2.31 & 2.30 & -0.4 & -3.87 & -4.30 & -11 & -4.54 & -17 & 0.093 & 0.073 & -21 & 0.086 & -7 \\
\hline 3 & 0.11 & 0.10 & 0.20 & 0.20 & 2.31 & 2.30 & -0.3 & -4.18 & -4.43 & -6 & -4.53 & -8 & 0.081 & 0.074 & -9 & 0.080 & -1 \\
\hline 3 & 0.11 & 0.10 & 0.00 & 0.00 & 2.31 & 2.31 & 0.0 & -4.45 & -4.55 & -2 & -4.55 & -2 & 0.075 & 0.073 & -3 & 0.075 & 0 \\
\hline
\end{tabular}

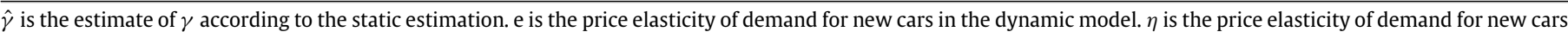

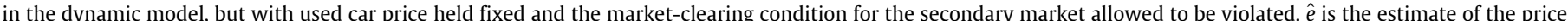

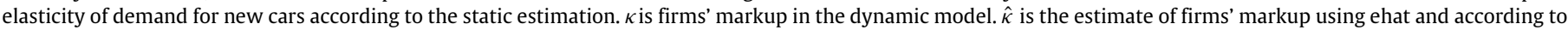
Lerner's index. $\tilde{\kappa}$ is the estimate of firms' markup using e and according to Lerner's index. Bias is calculated as (estimate - truevalue)/|true value|.

\subsubsection{Bias in static markup estimates}

The above subsection has shown that $\widehat{e}$ is a biased estimate of $e$, so $\widehat{\kappa}$ is bound to be a biased estimate of $\kappa$. But the bias in $\widehat{e}$ is not the only source of bias in $\widehat{\kappa}$. We want to show that even if the researcher has an unbiased estimate for $e$, his estimate for $\kappa$ will still be biased as long as $\beta_{1}>0$, because the FOC (28) used to infer the markup ignores dynamics on firms' side. To illustrate this point, we construct another estimate of the markup, one that uses the true elasticity, $e$, in the Lerner's index:

$\widetilde{\kappa}=-\frac{1}{N} / e$.

Our previous analysis suggests that the bias in the static markup's estimates comes from two sources, the bias in the static estimate of elasticity and the fact that the static FOC ignores the supply-side dynamics. The mechanism for the first source is straightforward. Regarding the second source, we note that in the dynamic model, firm $n$ chooses its quantity $q_{n}$ to maximize $\pi_{n}+\beta_{1} E_{c^{\prime}} W^{*}\left(K_{2}^{\prime}, c^{\prime}\right)$, rather than to maximize $\pi_{n}$. Let $\psi \equiv$ $\beta_{1} E_{c^{\prime}} W^{*}\left(K_{2}^{\prime}, c^{\prime}\right)$ denote the difference between the dynamic and static profit objectives. The true first order condition is

$\frac{\partial\left(\pi_{n}+\psi\right)}{\partial q_{n}}=\frac{\partial \pi_{n}}{\partial q_{n}}+\frac{\partial \psi}{\partial q_{n}}=0$.

We can sign the second term as

$\frac{\partial \psi}{\partial q_{n}}=\beta_{1} E \frac{\partial W^{*}}{\partial K_{2}^{\prime}} \frac{\partial K_{2}^{\prime}}{\partial q_{n}}$.
Since $\partial W^{*} / \partial K_{2}^{\prime}<0$ and $\partial K_{2}^{\prime} / \partial q_{n}>0$, we know $\partial \psi / \partial q_{n}<0$ as long as $\beta_{1}>0$, for all values of $q_{n}$. This implies that

$$
\begin{aligned}
& \frac{\partial \pi_{n}}{\partial q_{n}}>0 \\
& \Longrightarrow p_{1}-c+q_{n} \frac{\partial p_{1}}{\partial Q} \frac{\partial Q}{\partial q_{n}}>0 \\
& \Longrightarrow \frac{p_{1}-c}{p_{1}}+\frac{q_{n}}{Q} \frac{\partial p_{1}}{\partial Q} \frac{Q}{p_{1}}>0 \\
& \Longrightarrow \kappa=\frac{p_{1}-c}{p_{1}}>-\frac{1}{N} / e=\tilde{\kappa} .
\end{aligned}
$$

That is, even when the true elasticity is used, the static $\widetilde{\kappa}$ still underestimates the firms' markup.

To examine the bias in the markup estimates, we again look at the three sets of counterfactuals with various combinations of firms' and consumers' forward-lookingness. The markup results are reported alongside the elasticity results in Tables 3-5.

We find that the biases in $\widehat{\kappa}$ range from $-3 \%$ to $-59 \%$. The magnitude of the biases increases in both $\beta_{1}$ and $\beta_{2}$, which is expected, because the biases arise essentially from ignoring the intertemporal linkages deriving from firms' and consumers' forward-looking behavior. Even when $\beta_{1}=\beta_{2}=0$ (as in the bottom lines of Tables 4 and 5 ), so that neither side of the market 
Table 6

Bias in elasticity and markup estimates - Triopoly, varying $\delta, \rho$, and $\gamma$.

\begin{tabular}{|c|c|c|c|c|c|c|c|c|c|c|c|c|c|c|c|c|c|}
\hline $\mathrm{N}$ & $\delta$ & $\rho$ & $\beta_{1}$ & $\beta_{2}$ & $\gamma$ & $\hat{\gamma}$ & Bias (\%) & $\mathrm{e}$ & $\eta$ & Bias (\%) & $\hat{e}$ & Bias (\%) & $\kappa$ & $\hat{\kappa}$ & Bias (\%) & $\tilde{\kappa}$ & Bias (\%) \\
\hline 3 & 0.05 & 0.05 & 0.96 & 0.96 & 1.50 & 1.47 & -2.0 & -2.33 & -3.22 & -38 & -3.40 & -46 & 0.211 & 0.098 & -53 & 0.143 & -32 \\
\hline 3 & 0.05 & 0.05 & 0.96 & 0.96 & 2.31 & 2.29 & -0.8 & -3.39 & -4.56 & -34 & -4.89 & -44 & 0.143 & 0.068 & -52 & 0.098 & -31 \\
\hline 3 & 0.05 & 0.05 & 0.96 & 0.96 & 3.00 & 3.03 & 0.9 & -4.41 & -5.74 & -30 & -6.24 & -42 & 0.108 & 0.053 & -50 & 0.076 & -30 \\
\hline 3 & 0.05 & 0.10 & 0.96 & 0.96 & 1.50 & 1.49 & -0.8 & -2.33 & -3.22 & -38 & -3.44 & -48 & 0.211 & 0.097 & -54 & 0.143 & -32 \\
\hline 3 & 0.05 & 0.10 & 0.96 & 0.96 & 2.31 & 2.26 & -2.1 & -3.06 & -4.36 & -43 & -4.80 & -57 & 0.151 & 0.070 & -54 & 0.109 & -28 \\
\hline 3 & 0.05 & 0.10 & 0.96 & 0.96 & 3.00 & 3.00 & 0.1 & -2.96 & -4.55 & -54 & -5.97 & -102 & 0.151 & 0.056 & -63 & 0.113 & -25 \\
\hline 3 & 0.05 & 0.20 & 0.96 & 0.96 & 1.50 & 1.52 & 1.2 & -2.32 & -3.20 & -38 & -3.53 & -52 & 0.216 & 0.095 & -56 & 0.144 & -33 \\
\hline 3 & 0.05 & 0.20 & 0.96 & 0.96 & 2.31 & 2.35 & 1.6 & -2.16 & -3.45 & -60 & -4.78 & -121 & 0.200 & 0.070 & -65 & 0.154 & -23 \\
\hline 3 & 0.05 & 0.20 & 0.96 & 0.96 & 3.00 & 2.99 & -0.3 & -4.57 & -5.81 & -27 & -6.16 & -35 & 0.102 & 0.054 & -47 & 0.073 & -28 \\
\hline 3 & 0.11 & 0.05 & 0.96 & 0.96 & 1.50 & 1.50 & 0.0 & -1.96 & -3.03 & -55 & -3.50 & -78 & 0.249 & 0.095 & -62 & 0.170 & -32 \\
\hline 3 & 0.11 & 0.05 & 0.96 & 0.96 & 2.31 & 2.31 & 0.2 & -2.85 & -4.18 & -47 & -4.90 & -72 & 0.170 & 0.068 & -60 & 0.117 & -31 \\
\hline 3 & 0.11 & 0.05 & 0.96 & 0.96 & 3.00 & 3.00 & 0.1 & -3.66 & -5.17 & -42 & -6.10 & -67 & 0.132 & 0.055 & -58 & 0.091 & -31 \\
\hline 3 & 0.11 & 0.10 & 0.96 & 0.96 & 1.50 & 1.50 & 0.0 & -1.96 & -3.03 & -55 & -3.50 & -79 & 0.249 & 0.095 & -62 & 0.170 & -32 \\
\hline 3 & 0.11 & 0.10 & 0.96 & 0.96 & 2.31 & 2.26 & -2.1 & -2.85 & -4.19 & -47 & -4.79 & -68 & 0.170 & 0.070 & -59 & 0.117 & -31 \\
\hline 3 & 0.11 & 0.10 & 0.96 & 0.96 & 3.00 & 3.04 & 1.4 & -3.65 & -5.17 & -42 & -6.17 & -69 & 0.131 & 0.054 & -59 & 0.091 & -30 \\
\hline 3 & 0.11 & 0.20 & 0.96 & 0.96 & 1.50 & 1.49 & -0.8 & -1.96 & -3.03 & -54 & -3.48 & -77 & 0.250 & 0.096 & -62 & 0.170 & -32 \\
\hline 3 & 0.11 & 0.20 & 0.96 & 0.96 & 2.31 & 2.30 & -0.6 & -2.85 & -4.20 & -47 & -4.87 & -71 & 0.171 & 0.069 & -60 & 0.117 & -32 \\
\hline 3 & 0.11 & 0.20 & 0.96 & 0.96 & 3.00 & 3.02 & 0.7 & -3.66 & -5.18 & -41 & -6.15 & -68 & 0.132 & 0.054 & -59 & 0.091 & -31 \\
\hline 3 & 0.25 & 0.05 & 0.96 & 0.96 & 1.50 & 1.50 & -0.1 & -1.61 & -2.56 & -59 & -3.34 & -107 & 0.278 & 0.100 & -64 & 0.207 & -26 \\
\hline 3 & 0.25 & 0.05 & 0.96 & 0.96 & 2.31 & 2.33 & 0.9 & -2.47 & -3.54 & -43 & -4.64 & -88 & 0.181 & 0.072 & -60 & 0.135 & -25 \\
\hline 3 & 0.25 & 0.05 & 0.96 & 0.96 & 3.00 & 2.96 & -1.2 & -3.30 & -4.40 & -33 & -5.65 & -71 & 0.134 & 0.059 & -56 & 0.101 & -24 \\
\hline 3 & 0.25 & 0.10 & 0.96 & 0.96 & 1.50 & 1.51 & 0.6 & -1.62 & -2.57 & -59 & -3.37 & -108 & 0.279 & 0.099 & -64 & 0.206 & -26 \\
\hline 3 & 0.25 & 0.10 & 0.96 & 0.96 & 2.31 & 2.29 & -0.8 & -2.46 & -3.53 & -44 & -4.56 & -85 & 0.181 & 0.073 & -60 & 0.136 & -25 \\
\hline 3 & 0.25 & 0.10 & 0.96 & 0.96 & 3.00 & 3.02 & 0.8 & -3.30 & -4.40 & -33 & -5.77 & -75 & 0.133 & 0.058 & -57 & 0.101 & -24 \\
\hline 3 & 0.25 & 0.20 & 0.96 & 0.96 & 1.50 & 1.48 & -1.2 & -1.61 & -2.56 & -59 & -3.30 & -105 & 0.278 & 0.101 & -64 & 0.207 & -26 \\
\hline 3 & 0.25 & 0.20 & 0.96 & 0.96 & 2.31 & 2.32 & 0.6 & -2.46 & -3.53 & -44 & -4.63 & -88 & 0.181 & 0.072 & -60 & 0.136 & -25 \\
\hline 3 & 0.25 & 0.20 & 0.96 & 0.96 & 3.00 & 2.99 & -0.2 & -3.30 & -4.40 & -33 & -5.71 & -73 & 0.134 & 0.058 & -56 & 0.101 & -25 \\
\hline
\end{tabular}

Table 7

Bias in elasticity and markup estimates - Duopoly, varying $\delta, \rho$, and $\gamma$.

\begin{tabular}{|c|c|c|c|c|c|c|c|c|c|c|c|c|c|c|c|c|c|}
\hline $\mathrm{N}$ & $\delta$ & $\rho$ & $\beta_{1}$ & $\beta_{2}$ & $\gamma$ & $\hat{\gamma}$ & Bias (\%) & e & $\eta$ & Bias (\%) & $\hat{e}$ & Bias (\%) & $\kappa$ & $\hat{\kappa}$ & Bias (\%) & $\tilde{\kappa}$ & Bias (\%) \\
\hline 2 & 0.05 & 0.05 & 0.96 & 0.96 & 1.50 & 1.47 & -2.2 & -2.78 & -3.83 & -38 & -4.08 & -46 & 0.343 & 0.123 & -64 & 0.180 & -48 \\
\hline 2 & 0.05 & 0.05 & 0.96 & 0.96 & 2.31 & 2.28 & -1.2 & -3.77 & -5.12 & -36 & -5.56 & -47 & 0.249 & 0.090 & -64 & 0.133 & -47 \\
\hline 2 & 0.05 & 0.05 & 0.96 & 0.96 & 3.00 & 3.07 & 2.2 & -4.61 & -6.18 & -34 & -7.00 & -52 & 0.199 & 0.071 & -64 & 0.109 & -46 \\
\hline 2 & 0.05 & 0.10 & 0.96 & 0.96 & 1.50 & 1.49 & -0.8 & -2.79 & -3.83 & -37 & -4.13 & -48 & 0.342 & 0.121 & -65 & 0.179 & -48 \\
\hline 2 & 0.05 & 0.10 & 0.96 & 0.96 & 2.31 & 2.28 & -1.4 & -3.78 & -5.12 & -35 & -5.55 & -47 & 0.249 & 0.090 & -64 & 0.132 & -47 \\
\hline 2 & 0.05 & 0.10 & 0.96 & 0.96 & 3.00 & 3.01 & 0.2 & -4.61 & -6.18 & -34 & -6.87 & -49 & 0.199 & 0.073 & -63 & 0.108 & -46 \\
\hline 2 & 0.05 & 0.20 & 0.96 & 0.96 & 1.50 & 1.52 & 1.0 & -2.79 & -3.84 & -38 & -4.22 & -51 & 0.342 & 0.119 & -65 & 0.179 & -48 \\
\hline 2 & 0.05 & 0.20 & 0.96 & 0.96 & 2.31 & 2.36 & 2.3 & -3.76 & -5.11 & -36 & -5.76 & -53 & 0.250 & 0.087 & -65 & 0.133 & -47 \\
\hline 2 & 0.05 & 0.20 & 0.96 & 0.96 & 3.00 & 2.97 & -0.9 & -4.63 & -6.19 & -34 & -6.80 & -47 & 0.199 & 0.074 & -63 & 0.108 & -46 \\
\hline 2 & 0.11 & 0.05 & 0.96 & 0.96 & 1.50 & 1.50 & 0.0 & -2.39 & -3.63 & -52 & -4.26 & -78 & 0.381 & 0.118 & -69 & 0.209 & -45 \\
\hline 2 & 0.11 & 0.05 & 0.96 & 0.96 & 2.31 & 2.31 & 0.2 & -3.26 & -4.73 & -45 & -5.61 & -72 & 0.274 & 0.089 & -68 & 0.153 & -44 \\
\hline 2 & 0.11 & 0.05 & 0.96 & 0.96 & 3.00 & 3.00 & 0.0 & -4.06 & -5.67 & -40 & -6.76 & -66 & 0.216 & 0.074 & -66 & 0.123 & -43 \\
\hline 2 & 0.11 & 0.10 & 0.96 & 0.96 & 1.50 & 1.50 & 0.0 & -2.39 & -3.63 & -52 & -4.26 & -78 & 0.381 & 0.118 & -69 & 0.210 & -45 \\
\hline 2 & 0.11 & 0.10 & 0.96 & 0.96 & 2.31 & 2.28 & -1.3 & -3.26 & -4.73 & -45 & -5.53 & -70 & 0.274 & 0.090 & -67 & 0.153 & -44 \\
\hline 2 & 0.11 & 0.10 & 0.96 & 0.96 & 3.00 & 3.05 & 1.6 & -4.06 & -5.67 & -40 & -6.87 & -69 & 0.217 & 0.073 & -66 & 0.123 & -43 \\
\hline 2 & 0.11 & 0.20 & 0.96 & 0.96 & 1.50 & 1.49 & -0.9 & -2.39 & -3.63 & -52 & -4.22 & -76 & 0.381 & 0.119 & -69 & 0.209 & -45 \\
\hline 2 & 0.11 & 0.20 & 0.96 & 0.96 & 2.31 & 2.29 & -0.7 & -3.27 & -4.73 & -45 & -5.57 & -71 & 0.275 & 0.090 & -67 & 0.153 & -44 \\
\hline 2 & 0.11 & 0.20 & 0.96 & 0.96 & 3.00 & 3.02 & 0.8 & -4.07 & -5.68 & -40 & -6.83 & -68 & 0.217 & 0.073 & -66 & 0.123 & -43 \\
\hline 2 & 0.25 & 0.05 & 0.96 & 0.96 & 1.50 & 1.50 & -0.1 & -2.01 & -3.03 & -51 & -3.98 & -98 & 0.391 & 0.126 & -68 & 0.249 & -36 \\
\hline 2 & 0.25 & 0.05 & 0.96 & 0.96 & 2.31 & 2.33 & 1.0 & -2.87 & -3.96 & -38 & -5.24 & -83 & 0.270 & 0.095 & -65 & 0.175 & -35 \\
\hline 2 & 0.25 & 0.05 & 0.96 & 0.96 & 3.00 & 2.96 & -1.4 & -3.69 & -4.78 & -29 & -6.22 & -68 & 0.208 & 0.080 & -61 & 0.135 & -35 \\
\hline 2 & 0.25 & 0.10 & 0.96 & 0.96 & 1.50 & 1.51 & 0.6 & -2.01 & -3.03 & -51 & -4.01 & -100 & 0.391 & 0.125 & -68 & 0.249 & -36 \\
\hline 2 & 0.25 & 0.10 & 0.96 & 0.96 & 2.31 & 2.29 & -0.8 & -2.87 & -3.96 & -38 & -5.15 & -80 & 0.270 & 0.097 & -64 & 0.175 & -35 \\
\hline 2 & 0.25 & 0.10 & 0.96 & 0.96 & 3.00 & 3.03 & 0.8 & -3.70 & -4.78 & -29 & -6.37 & -72 & 0.208 & 0.079 & -62 & 0.135 & -35 \\
\hline 2 & 0.25 & 0.20 & 0.96 & 0.96 & 1.50 & 1.48 & -1.3 & -2.01 & -3.03 & -51 & -3.93 & -96 & 0.391 & 0.127 & -67 & 0.249 & -36 \\
\hline 2 & 0.25 & 0.20 & 0.96 & 0.96 & 2.31 & 2.33 & 0.7 & -2.87 & -3.96 & -38 & -5.23 & -82 & 0.270 & 0.096 & -65 & 0.174 & -35 \\
\hline 2 & 0.25 & 0.20 & 0.96 & 0.96 & 3.00 & 2.99 & -0.2 & -3.70 & -4.78 & -29 & -6.30 & -70 & 0.208 & 0.079 & -62 & 0.135 & -35 \\
\hline
\end{tabular}

is forward-looking, $\widehat{\kappa}$ is still biased by $-3 \%$, resulting from a biased estimate of elasticity, which in turn results from ignoring the impact of new car production on used car price and the consequent effect on new car demand.

The markup $\widetilde{\kappa}$, which uses the true elasticity in the Lerner's index, is found to be downward biased unless $\beta_{1}=\beta_{2}=0$. The biases range from $-31 \%$ to $0 \%$, with the baseline parameterization yielding the largest bias at $-31 \%$. These results confirm that if firms are forward-looking and we use the static FOC that ignores the supply-side dynamics to infer firms' markup, we will underestimate the markup.

\subsection{Robustness checks}

We perform robustness checks by varying $N$ (the number of firms), $\delta$ (the probability of used car depreciation), $\rho$ (the cost shock probability), and $\gamma$ (the consumers' marginal utility of money). Tables 6 and 7 report the results for all parameterizations such that $N \in\{2,3\}, \delta \in\{0.05,0.11,0,25\}, \rho \in\{0.05,0.1,0,2\}$, and $\gamma \in\{1.5,2.31,3\}$. Throughout, $\beta_{1}$ and $\beta_{2}$ are fixed at $1 / 1.04$.

The results reported in Tables 6 and 7 show that when the firms and consumers are forward-looking, the static estimates of the elasticities and markups are substantially biased. In fact, the range for the percentage biases is $(-121 \%,-35 \%)$ for $\widehat{e},(-69 \%,-47 \%)$ 
for $\widehat{\kappa}$, and $(-48 \%,-23 \%)$ for $\widetilde{\kappa}$. In contrast, the biases in $\widehat{\gamma}$ is small, ranging from $-2 \%$ to $2 \%$.

Our basic conclusions above regarding the directions of the biases are robust to different parameterizations: the static estimate of the elasticity is an overestimate of the true elasticity, and the static estimate of the firms' markup is an underestimate.

\section{Conclusion}

In this paper, we conduct a simulation study to demonstrate and quantify the bias from ignoring dynamics in estimating models of durable-goods markets. The bias has two sources. The first source comes from ignoring the consumers' forwardlooking behavior. This first type of bias has also been a focus of the more recent work on estimating dynamic models of durable-good demand (e.g. Gowrisankaran and Rysman (2006), Carranza (2007), Gordon (2006), among others). The second source of bias derives from ignoring firms' forward-looking behavior. As far as we are aware, this is the first paper that quantifies this second type of bias. We find that ignoring dynamics leads to upwardly-biased (in absolute terms) estimates of demand elasticities and, consequently, downwardly-biased estimates of markups. Furthermore, we find that, in practice, the second type of bias is larger in magnitude than the first type of bias. This suggests that a correct specification of firm behavior is crucial in order to draw correct policy implications for durable-good markets.

\section{References}

Adda, J., Cooper, R., 2000a. Balladurette and Jupette: A discrete analysis of scrapping subsidies. Journal of Political Economy 108, 778-806.

Adda, J., Cooper, R., 2000b. The dynamics of car sales: A discrete-choice approach, NBER Working Paper \#7785.

Akerlof, G., 1970. The market for lemons: Quality uncertainty and the market mechanism. Quarterly Journal of Economics 84, 488-500.

Ausubel, L., Deneckere, R., 1989. Reputation in bargaining and durable goods monopoly. Econometrica 58, 511-531.

Berkovec, J., 1985. New car sales and used car stocks: A model of the automobile market. RAND Journal of Economics 16, 195-214.

Berry, S., 1994. Estimating discrete choice models of product differentiation. RAND Journal of Economics 25, 242-262.

Berry, S., Levinsohn, J., Pakes, A., 1995. Automobile prices in market equilibrium. Econometrica 63, 841-890.

Bond, E., 1982. A direct test of the lemons model: The market for used pickup trucks. American Economic Review 72, 836-840.

Bond, E., Samuelson, L., 1984. Durable good monopolies with rational expectations and replacement sales. RAND Journal of Economics 15, 336-345.

Bresnahan, T., 1987. Competition and collusion in the American auto industry: The 1955 price war. Journal of Industrial Economics 35, 457-482.

Bulow, J., 1982. Durable-goods monopolists. Journal of Political Economy 90 314-332.

Carlton, D., Gertner, R., 1989. Market power and mergers in durable-good industries. Journal of Law and Economics 32, S203-S231.

Carranza, J.E., 2007. Estimation of demand for differentiated durable goods, manuscript, University of Wisconsin.

Carranza, J.E., 2008. Product innovation and adoption in market equilibrium: The case of digital cameras, manuscript, University of Wisconsin.

Chen, J., Esteban, S., Shum, M., 2007. How much competition is a secondary market, manuscript, John Hopkins University.

Chevalier, J., Goolsbee, A., 2003. Measuring prices and price competition online: Amazon and Barnes and Noble. Quantitative Marketing and Economics 1, 203-222.

Clerides, S., 2003. The welfare effects of trade liberalization: Evidence from used automobiles, manuscript, University of Cyprus.
Coase, R., 1972. Durability and monopoly. Journal of Law and Economics 15, 143-149.

Copeland, A., Dunn, W., Hall, G., 2005. Prices, production, and inventories over the automotive model year, NBER Working Paper, \#11257.

Erdem, T., Imai, S., Keane, M., 2003. Brand and quantity choice dynamics under price uncertainty. Quantitative Marketing and Economics 1, 5-64.

Esteban, S., 1999. Semi-durable goods and imperfect competition, Ph.D. Thesis, University of Rochester.

Esteban, S., 2002. Equilibrium dynamics in semi-durable goods markets, manuscript, Penn State University.

Esteban, S., Shum, M., 2007. Durable goods oligopoly with secondary markets: The case of automobiles. RAND Journal of Economics 38, 332Ü-354.

Goettler, R., Gordon, B., 2008. Durable goods oligopoly with innovation: Theory and empirics, manuscript, Carnegie Mellon University.

Goldberg, P., 1995. Product differentiation and oligopoly in international markets: The case of the US automobile industry. Econometrica 63, 891-951.

Gordon, B., 2006. Estimating a dynamic model of demand for durable goods, manuscript, Columbia University.

Gowrisankaran, G., Rysman, M., 2006. Dynamics of consumer demand for new durable goods, manuscript, Boston University.

Gul, F., Sonnenschein, H., Wilson, R., 1986. Foundations of dynamic monopoly and the coase conjecture. Journal of Economic Theory 39, 155-190.

Hartmann, W., 2006. Intertemporal effects of consumption and their implications for demand elasticity estimates. Quantitative Marketing and Economics 4 325-349.

Hendel, I., Lizzeri, A., 1999. Adverse selection in durable goods markets. American Economic Review 89, 1097-1115.

Hendel, I., Nevo, A., 2006. Measuring the implications of sales and consumer inventory behavior. Econometrica 74, 1637-1673.

House, C., Leahy, J., 2000. An (s,S) model with adverse selection, NBER working paper, \#8030.

Iizuka, T., 2007. An empirical analysis of planned obsolescence. Journal of Economics and Management Strategy 1, 191-226.

Judd, K., 1998. Numerical Methods in Economics. The MIT Press, Cambridge, MA.

Liang, M., 1999. Does a second-hand market limit a durable goods monopolist's market power?, manuscript, University of Western Ontario.

Melnikov, O., 2000. Demand for differentiated durable products: The case of the US computer printer market, manuscript, Cornell University.

Miranda, M., Fackler, P., 2002. Applied Computational Economics and Finance. The MIT Press, Cambridge, MA.

Nair, H., 2004. Dynamics of pricing in durable goods markets: Application to 32-bit console games, manuscript, Stanford University.

Petrin, A., 2002. Quantifying the benefits of new products: The case of the minivan. Journal of Political Economy 110, 705-729.

Porter, R., Sattler, P., 1999. Patterns of trade in the market for used durables: Theory and evidence, NBER working paper, \#7149.

Ramey, V., 1989. Durable goods monopoly behavior in the automobile industry, manuscript, UC-San Diego.

Rust, J., 1985. Stationary equilibrium in a market for durable assets. Econometrica $53,783-805$.

Song, I., Chintagunta, P., 2003. A micromodel of new product adoption with heterogeneous and forward-looking consumers: Application to the digital camera category. Quantitative Marketing and Economics 1, 371-407.

Stokey, N., 1981. Rational expectations and durable goods pricing. Bell Journal of Economics 12, 112-128.

Stolyarov, D., 2002. Turnover of used durables in a stationary equilibrium: Are older goods traded more? Journal of Political Economy 110, 1390-1413.

Sun, B., Neslin, S., Srinivasan, K., 2003. Measuring the impact of promotions on brand switching when consumers are forward-looking. Journal of Marketing Research $40,389-405$.

Suslow, V., 1986. Estimating monopoly behavior with competition recycling: An application to alcoa. RAND Journal of Economics 17, 389-403.

Tanaka, M., 2007. Durable goods oligopoly and the Tokyo condominium market in the 1990s, Manuscript, John Hopkins University.

Train, K., 2003. Discrete Choice Methods with Simulation. Cambridge University Press.

Waldman, M., 2003. Durable goods theory for real world markets. Journal of Economic Perspectives 17, 131-154.

Wang, Y., 2007. Empirical investigation of durability in the US automobile market, manuscript, New York University.

Wooldridge, J., 2002. Econometric Analysis of Cross Section and Panel Data. The MIT Press, Cambridge, MA. 